\title{
Evaluation and clinical significance of the stomach age model for evaluating aging of the stomach-a multicenter study in China
}

Qin-Yan Gao ${ }^{1,2,3}$, Zhen-Hua Wang ${ }^{1,2,3}$, Yun Cui ${ }^{1,2,3}$, Jian-Qiu Sheng ${ }^{4}$, Kun-He Zhang ${ }^{5}$, Rui-Hua Shi ${ }^{6}$, Jian-Ming X X ${ }^{7}$, Wei-Chang Chen ${ }^{8}$, Xiu-Li Zuo ${ }^{9}$, Shu-De Li ${ }^{10}$, Yue-Xiang Chen ${ }^{11}$, Yan-Yan Song ${ }^{12}$ and Jing-Yuan Fang ${ }^{1,2,3^{*}}$

\begin{abstract}
Background: A higher prevalence of chronic atrophic gastritis (CAG) occurs in younger adults in Asia. We used Stomach Age to examine the different mechanisms of CAG between younger adults and elderly individuals, and established a simple model of cancer risk that can be applied to CAG surveillance.

Methods: Stomach Age was determined by FISH examination of telomere length in stomach biopsies. $\Delta \psi m$ was also determined by flow cytometry. Sixty volunteers were used to confirm the linear relationship between telomere length and age while 120 subjects were used to build a mathematical model by a multivariate analysis. Overall, 146 subjects were used to evaluate the validity of the model, and 1,007 subjects were used to evaluate the relationship between prognosis and $\Delta$ age (calculated from the mathematical model). ROC curves were used to evaluate the relationship between prognosis and $\Delta$ age and to determine the cut-off point for $\Delta$ age.

Results: We established that a tight linear relationship between the telomere length and the age. The telomere length was obvious different between patients with and without CAG even in the same age. $\Delta \psi \mathrm{m}$ decreased in individuals whose Stomach Age was greater than real age, especially in younger adults. A mathematical model of Stomach Age (real age $+\Delta$ age) was successfully constructed which was easy to apply in clinical work. A higher $\Delta$ age was correlated with a worse outcome. The criterion of $\Delta$ age $>3.11$ should be considered as the cut-off to select the subgroup of patients who require endoscopic surveillance.

Conclusion: Variation in Stomach Age between individuals of the same biological age was confirmed. Attention should be paid to those with a greater Stomach Age, especially in younger adults. The $\Delta$ age in the Simple Model can be used as a criterion to select CAG patients for gastric cancer surveillance.
\end{abstract}

Keywords: Stomach Age, Chronic atrophic gastritis, Gastric cancer surveillance, Model

\section{Background}

Chronic atrophic gastritis (CAG) was listed as precancerous condition for gastric cancer by the WHO in 1978. It has been observed that a moderately increased risk of gastric cancer with the presence of CAG after 10 years of follow-up [1]. Because CAG tends to be lifelong, and

\footnotetext{
* Correspondence: jingyuanfang2007@126.com

${ }^{1} \mathrm{Gl}$ Division, Renji Hospital, Shanghai Jiao-Tong University School of Medicine, Shanghai Institution of Digestive Disease, 145 Middle Shandong Rd, Shanghai 200001, China

${ }^{2}$ Key Laboratory of Gastroenterology \& Hepatology, Ministry of Health, Shanghai Jiao-Tong University, 145 Middle Shandong Rd, Shanghai 200001, China

Full list of author information is available at the end of the article
}

spontaneous healing is rare [2], it is no doubt that younger adults with CAG would have a higher risk of gastric cancer due to the long duration of disease.

Some experts believe that the pathological degenerative changes of CAG may be a semi-physiological phenomenon especially in the elderly population [3]. However, a high prevalence among younger adults is found in some high-risk regions for gastric cancer in Asia [4]. Our research seeks to investigate the different underlying causes of CAG between different age groups.

Telomere erosion can be regarded as a biological clock [5]. As telomeres shorten with age in humans and

\section{Biomed Central}

(c) 2014 Gao et al.; licensee BioMed Central Ltd. This is an Open Access article distributed under the terms of the Creative Commons Attribution License (http://creativecommons.org/licenses/by/2.0), which permits unrestricted use, distribution, and reproduction in any medium, provided the original work is properly credited. 
premature aging syndromes are often associated with shortened telomeres, it has been proposed that telomere length is an important parameter in aging. Telomere length reduction has been confirmed in diseases such as hypertension [6], diabetes and coronary heart disease $[7,8]$, and it has been also confirmed in cells of the human thyroid and parathyroid [9], as well as liver, kidney and skin [10]. However, whether this is also the case with CAG or in the stomach aging process remains unclear.

To address these questions, the quantification of telomere length is essential. Recent studies have described a method of fluorescence in situ hybridization (FISH) that is faster and more reliable than comparable techniques [11-14], which can also be applied to paraffin-embedded tissue samples [15]. Using FISH, we were able to measure the telomere length of chromosomes in stomach cells from biopsy samples obtained by endoscopy.

In this study, we define a new term of "Stomach Age", which can be used to evaluate the aging of the stomach and is based on the telomere length of stomach cells. We attempted to use this concept to explain the phenomenon of CAG in younger adults and to establish a simple mathematical model to calculate Stomach Age, which can be applied clinically for prognostication.

\section{Methods}

\section{Study subjects and archived tissue samples to establish} the Stomach Age model

Tissue samples were obtained from the pathology archives of the GI Division at Shanghai Jiao-Tong University School of Medicine, Renji Hospital and eight other medical centers (Military General Hospital of Beijing PLA, First Affiliated Hospital of Nanchang University, First Affiliated Hospital of Nanjing Medical University, First Affiliated Hospital of Anhui University, First Affiliated Hospital of Soo-Chow University, Qilu Hospital of Shandong University, Second Military Medical University, Changhai Hospital and Changzheng Hospital). Formalinfixed paraffin-embedded blocks were retrieved from 246 subjects (60 healthy volunteers and 186 out-patients at gastrointestinal clinical departments) who underwent endoscopy. At least two biopsies were taken from the antrum and corpus on both the greater curvature and the lesser curvature of the stomach, and then routinely embedded in paraffin blocks, sectioned and stained. Tissue sections $(3-4 \mu \mathrm{m})$ from each sample were used for the histopathological examination and FISH. Another two biopsies taken from the antrum were preserved in liquid nitrogen and kept at $-80^{\circ} \mathrm{C}$ for flow cytometry.

\section{Study population to evaluate the predictive ability of the Stomach Age model}

Relevant information from 1,200 patients at the Shanghai Jiao-Tong University School of Medicine, Renji Hospital was analyzed. At the baseline timepoint, all participants underwent endoscopic examination with biopsies, which were repeated at least once at subsequent visits during the follow-up period. The relevant information regarding the histological results and the answers to the questionnaire, described below, were recorded and compared between age groups.

\section{Questionnaire}

We interviewed all participants using a standard selfadministered questionnaire to assess baseline characteristics. The mean time for completing the questionnaire was approximately 15-20 minutes. The questionnaire included the following: 1) demographic factors; 2) any family history of medical conditions, including cancer; 3) a detailed medication history; 4) sleeping habits and quality, and job pressures; 5) the number of cigarettes smoked per day and the duration of smoking; 6) the frequency and amount of water, milk, beverages, wine and hard liquor taken; 7) tea and coffee drinking habits; 8) the consumption of rice, meat, fish, vegetables, fruits, pickled vegetables or salted fermented products, and dehydrated foods; and 9) favorite flavors, cooking methods, and intake of night snacks.

\section{Histopathological diagnosis and Helicobacter pylori infection assessment}

Each stained slide was examined independently by two experienced pathologists who were unaware of the individual's clinical details using the updated Sydney classification [16]. When there were disagreements, the biopsies were re-examined until agreement was reached. Two histopathological entities were defined: chronic nonatrophic gastritis (CNAG) and CAG. CNAG was defined as any grade of inflammation with no atrophy in both the corpus and the antrum. CAG was defined as atrophy or/and intestinal metaplasia (IM) in either the corpus or the antrum. The histological features of the biopsies were recorded as slight, moderate, or severe according to the Sydney scoring system. Patients with no or inadequate biopsies were excluded from the study. Helicobacter pylori infection was detected by either rapid urease testing of biopsy samples or [13] ${ }^{13-} \mathrm{C}$ urease breath test.

\section{FISH}

Hybridization was performed according to the manufacturer's instructions. Briefly, slides were deparaffinized and rehydrated through a series of ethanol gradients, treated with $0.1 \%$ Tween 20 detergent in de-ionized water, incubated in citrate buffer (Target Unmasking Solution; Vector Laboratories, Burlingame, USA) in steam, immersed in de-ionized water and fixed in ethanol gradients, and air-dried. Approximately $10 \mu \mathrm{l}$ of PNA probe was added to each slide. The PNA probe for telomeric 
sequences was a ready-to-use probe included in the Telomere PNA Fish Kit/FITC (K5327; DakoCytomation A/S, Glostrup. Denmark). The slides were then coverslipped, incubated at $84^{\circ} \mathrm{C}$ for $5 \mathrm{~min}$, and hybridized for $2 \mathrm{~h}$ at room temperature in the dark. After extensive washing, first at $65^{\circ} \mathrm{C}$ and then at room temperature with PBST. The nuclei were then stained with DAPI ( $1 \mu \mathrm{g} / \mathrm{ml}$, Molecular Probes, Eugene, OR), after washed in stilled water, the slides were mounted with antifade mounting media (Prolong ${ }^{\mathrm{Tm}}$ Anti-fade Mounting Media; Molecular Probes, Eugene, OR, USA).

\section{Microscopy and data analysis}

Slides were imaged using an epifluorescence microscope (Nikon Eclipse 80i). The fluorescence excitation/emission filters used were FITC $490 \mathrm{~nm}$ BP excitation via a XF38 filter set. Fluorescence images were captured with a cooled charge-coupled device camera (Nikon DSRil). For the tissue section, the calculated areas were identified according to the H\&E-stained slides before the fluorescence microscopy which contained the epithelial cells and the glands (pyloric glands in antrum and fundic glands in corpus). After that the calculated areas were divided into five regions automatically by the professional software (Image-Pro Plus 6.0). At least $1000 \mathrm{nu}$ clei were calculated in each region. Five regions of each tissue section were examined for telomere labeling; the intensity of the fluorescence was utilized to reflect this. Telomere signals were quantitated by a method validated recently in which the sum of pixel intensities in the FITC channel for a given cell nucleus is normalized to the DAPI signal. DAPI staining provides a robust measure of DNA content, being largely insensitive to cell type, proliferation status, and degree of chromatin condensation [17-19]. Each region of the tissue section was examined for telomere labeling independently by two experienced technicians at different time. The correlation coefficients were estimated.

\section{Flow cytometry and measurement of $\Delta \psi \mathrm{m}$}

$\Delta \psi \mathrm{m}$, the voltage across the inner mitochondrial membrane, can be altered by oxidative damage, such as that which occurs during the aging process. Studies showed that $\Delta \psi \mathrm{m}$ decreased gradually with age $[20,21]$. So we believed that $\Delta \psi \mathrm{m}$ can be used to evaluate the aging of the stomach and as a measurement to validate the term of "Stomach Age". To support our study, we determined the value of $\Delta \psi \mathrm{m}$ of those patients. Antrum biopsy samples were first prepared as single cell suspensions using a tissue dissociation kit according to the manufacturer's protocol (KGA829, KeyGEN Biology Co., Ltd, Nanjing, China). For staining, the cells were incubated with JC-1 (Molecular Probes, Invitrogen, Germany) for $30 \mathrm{~min}$ at $37^{\circ} \mathrm{C}$ in the dark. The cells were then washed in PBS and analyzed immediately by flow cytometry (FACScan; BD Biosciences, Franklin Lakes, NJ, USA). A total of 10,000 cells were examined for green fluorescence using a $529 \mathrm{~nm}$ filter and for orange fluorescence using a $590 \mathrm{~nm}$ filter. All data were analyzed using BD Cell Quest Pro Software (BD Biosciences).

\section{Statistical analysis}

Statistical analysis was performed using SPSS 17.0 statistical software. The paired $t$-test, Chi-square test and analysis of variance were used. All data were presented as the mean \pm SE. Differences were considered to be statistically significant at $P<0.05$. Multivariate analysis was performed by logistic regression using a backward elimination procedure for variables not significantly associated with the $\Delta$ age (Stomach Age-real age; $P=0.05$ ) [22]. The sensitivity and specificity of the models were calculated. The performance of the predictive model was assessed by the area under the receiver operating characteristic curve (AUROC). We chose the highest Youden's index as the optimal cut-off point [23].

\section{Ethics}

The study protocol was accepted by the Renji Hospital Ethics Committee (Shanghai, China). Each participant was required to sign an informed consent form.

\section{Results}

\section{Linear relationship between telomere length and age in} stomach cells

In order to evaluate the Stomach Age, we aimed to establish the standard criteria of Stomach Age in healthy people. Sixty antrum biopsies from healthy volunteers were used to establish the standard criteria. These included 30 males and 30 females aged 23-76 years, in whom endoscopy showed a generally normal gastric lining and in whom the Stomach Age was considered to be the same as their real age. Five regions of each tissue section were examined for the intensity of telomere labeling; the average intensity was used for the regression equation. The mean coefficient of variation was 0.097 which we consider satisfactory. The volunteers' characteristics and fluorescence intensity are listed in Table 1. As demonstrated in Figure 1, a tight linear relationship (goodness of fit: $r^{2}=0.8263$ ) existed between the intensity of telomere labeling and the age. The equation of the computed regression line is $x$ (years) $=(17.719-y) /$ 0.174 . In this equation, $y$ was the value of fluorescence intensity on FISH and $x$ was the age. The correlation coefficient between FISH data and age is $r=\sqrt{ } 0.8263=$ 0.91 . Thus, we clearly demonstrated a linear decline in telomere length with age increasing. By using the equation above the biological aging level of stomach (Stomach Age) of every one could be expressed precisely in 
Table 1 The characteristics and fluorescence intensity of volunteers

\begin{tabular}{|c|c|c|c|c|c|c|}
\hline Age range (years) & $21-30$ & $31-40$ & $41-50$ & $51-60$ & $61-70$ & $71-80$ \\
\hline Total number & 6 & 12 & 9 & 15 & 12 & 6 \\
\hline Number of male & 3 & 9 & 6 & 9 & 6 & 3 \\
\hline Fluorescence intensity (mean \pm SD) & $14.8 \pm 0.69$ & $11.8 \pm 0.92$ & $9 \pm 1.07$ & $7.87 \pm 1.64$ & $6.18 \pm 0.76$ & $6.15 \pm 0.04$ \\
\hline \multicolumn{7}{|l|}{ Occupation } \\
\hline Student & 3 & 0 & 0 & 0 & 0 & 0 \\
\hline Professional & 0 & 4 & 4 & 2 & 1 & 0 \\
\hline Administrative & 0 & 2 & 1 & 3 & 1 & 0 \\
\hline Sales & 1 & 3 & 1 & 0 & 0 & 0 \\
\hline Blue-collar & 1 & 2 & 1 & 0 & 0 & 0 \\
\hline Freelance & 1 & 1 & 2 & 0 & 0 & 0 \\
\hline Retired & 0 & 0 & 0 & 10 & 10 & 6 \\
\hline \multicolumn{7}{|l|}{ Family history } \\
\hline Stomach cancer & 0 & 0 & 0 & 0 & 0 & 0 \\
\hline Other cancer & 0 & 0 & 1 & 0 & 0 & 0 \\
\hline History of peptic ulcer & 0 & 0 & 0 & 0 & 0 & 0 \\
\hline Smoking status \& history & 0 & 2 & 2 & 1 & 1 & 0 \\
\hline Seldom & 0 & 1 & 0 & 0 & 1 & 0 \\
\hline$<10$ cigarettes per day & 0 & 1 & 2 & 1 & 0 & 0 \\
\hline 10-20 cigarettes per day & 0 & 0 & 0 & 0 & 0 & 0 \\
\hline$>20$ cigarettes per day & 0 & 0 & 0 & 0 & 0 & 0 \\
\hline Less than 5 years & 0 & 1 & 0 & 0 & 0 & 0 \\
\hline $5-10$ years & 0 & 1 & 1 & 0 & 0 & 0 \\
\hline More than 10 years & 0 & 0 & 1 & 1 & 1 & 0 \\
\hline Alcohol drinking habits & 0 & 2 & 1 & 2 & 1 & 0 \\
\hline$<250 \mathrm{ml}$ per day & 0 & 2 & 1 & 2 & 0 & 0 \\
\hline$>250 \mathrm{ml}$ per day & 0 & 0 & 0 & 0 & 0 & 0 \\
\hline Less than 5 years & 0 & 1 & 0 & 0 & 0 & 0 \\
\hline More than 5 years & 0 & 1 & 1 & 2 & 1 & 0 \\
\hline Coffee habits & 2 & 1 & 0 & 0 & 0 & 0 \\
\hline Tea drinking habits & 1 & 2 & 2 & 1 & 0 & 1 \\
\hline
\end{tabular}

terms of the intensity of fluorescence on FISH and compared individually.

\section{Different telomere lengths between CAG and CNAG patients}

Secondly, we found that telomere length was obvious different between patients with and without CAG. At the same age, the intensity of the fluorescence of was lower in CAG patients than CNAG patients (Figure 2), which suggests that CAG may accelerate stomach aging. This change can make the degree of stomach aging in young patients with CAG equivalent to that of elderly individuals. Therefore, we postulated that people of the same biological age may have a different Stomach Age, which could be influenced by risk factors such as gastric atrophy and IM.
Flow cytometry and measurement of $\Delta \psi m$

To obtain further evidence to support our hypothesis, we determined the value of $\Delta \psi \mathrm{m}$. If CAG do accelerate stomach aging, the $\Delta \psi \mathrm{m}$ of those patients should decrease simultaneously.

JC-1 (5',6,6'-tetrachloro-1,1'3,3'-tetraethylbenzimidazolylcarbocyanine iodide) can be used as an indicator of mitochondrial potential, which, when damaged, plays a central role in the aging process [24]. In cells that have mitochondria with a high $\Delta \psi \mathrm{m}, \mathrm{JC}-1$ forms orange fluorescent J-aggregates (Q2 region), whereas in cells with depolarized or damaged mitochondria, the sensor dye is present as green fluorescent monomers (Q4 region). We calculated the telomere length of enrolled subjects (146 subjects), and then obtained the Stomach Age of those subjects by using the Stomach Age equation (obtained 


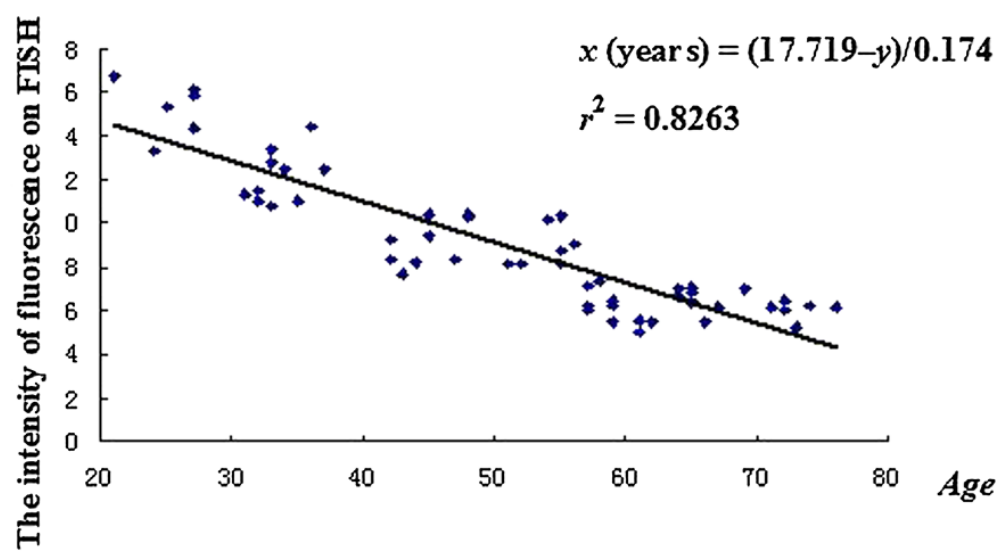

Figure 1 Stomach Age of volunteers. The volunteers' age and the intensity of fluorescence on fluorescence in situ hybridization are closely correlated in a linear manner $\left(r^{2}=0.8263\right)$ when a simple regression analysis is applied $(y=-0.174 x+17.719$, where $y$ is fluorescence intensity and $x$ is Stomach Age). Rearranging this equation, the Stomach Age model is $x$ (years) $=(17.719-y) / 0.174$.

from the health volunteers). After that, we compared their $\Delta \psi \mathrm{m}$ values.

We defined individuals below 50 years of age as the younger adult group, and individuals aged $\geq 50$ years were the older adult group (Figure 3). In CNAG patients of younger adults, the Stomach Ages were younger than or equal to their real age, most of the sample cells were localized in the Q2 region (high $\Delta \psi \mathrm{m}$ ). However, in CAG patients of younger adults, the Stomach Ages were greater than their real age, most cellular dots shifted from Q2 to the Q4 region, indicating a loss of $\Delta \psi \mathrm{m}$, and the relative ratio of cellular dots in the Q2 regions decreased significantly $(P<0.05)$. The same trend occurred in the older adults, but the shift in ratio was not as great as in the younger group. These results indicate that CAG could accelerate stomach aging accompany with the decreasing of $\Delta \psi \mathrm{m}$. The $\Delta \psi \mathrm{m}$ was decreased in individuals whose Stomach Age was greater than their real age, especially in younger adults $(P<0.05)$. Stomach Age can represent the biological age of the stomach more precisely than the true biological age.

\section{Evaluation and establishment of the Simple Model in a multicenter study}

For use in clinical practice, we tried to modify the equation of the Stomach Age to obtain a Simple Model. 120 samples including 60 volunteers were used (The detailed characteristics are listed in Table 2). Firstly, we measured the samples' intensity on FISH, and then calculated each individual's Stomach Age using the equation.

We also collected their baseline variables from a questionnaire and the histological information, and several risk
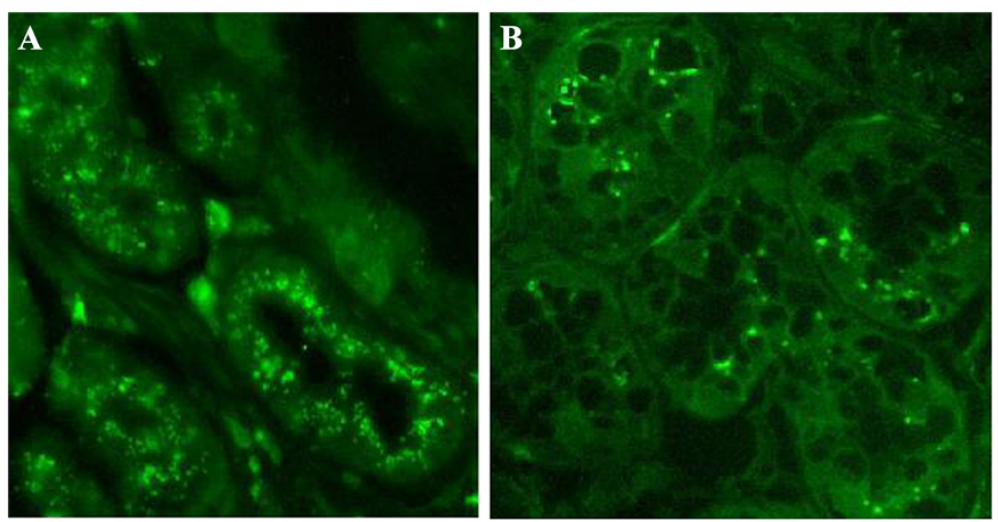

Figure 2 Fluorescence in situ hybridization (FISH) of stomach biopsies. FISH was performed on biopsy samples obtained from patients by endoscopy. Telomeres are stained with a FITC-labeled antitelomeric probe and are colored green. Picture $\mathbf{A}$ (male, 40 years old, endoscopy result: CNAG) demonstrates strong telomeric signals in normal stomach. Picture B (male, 40 years old, endoscopy result: CAG with moderate intestinal metaplasia) demonstrates weak telomeric signals in atrophic tissue, indicating that CAG may accelerate aging of the stomach. Original magnification: $\times 40$ (A, B). 


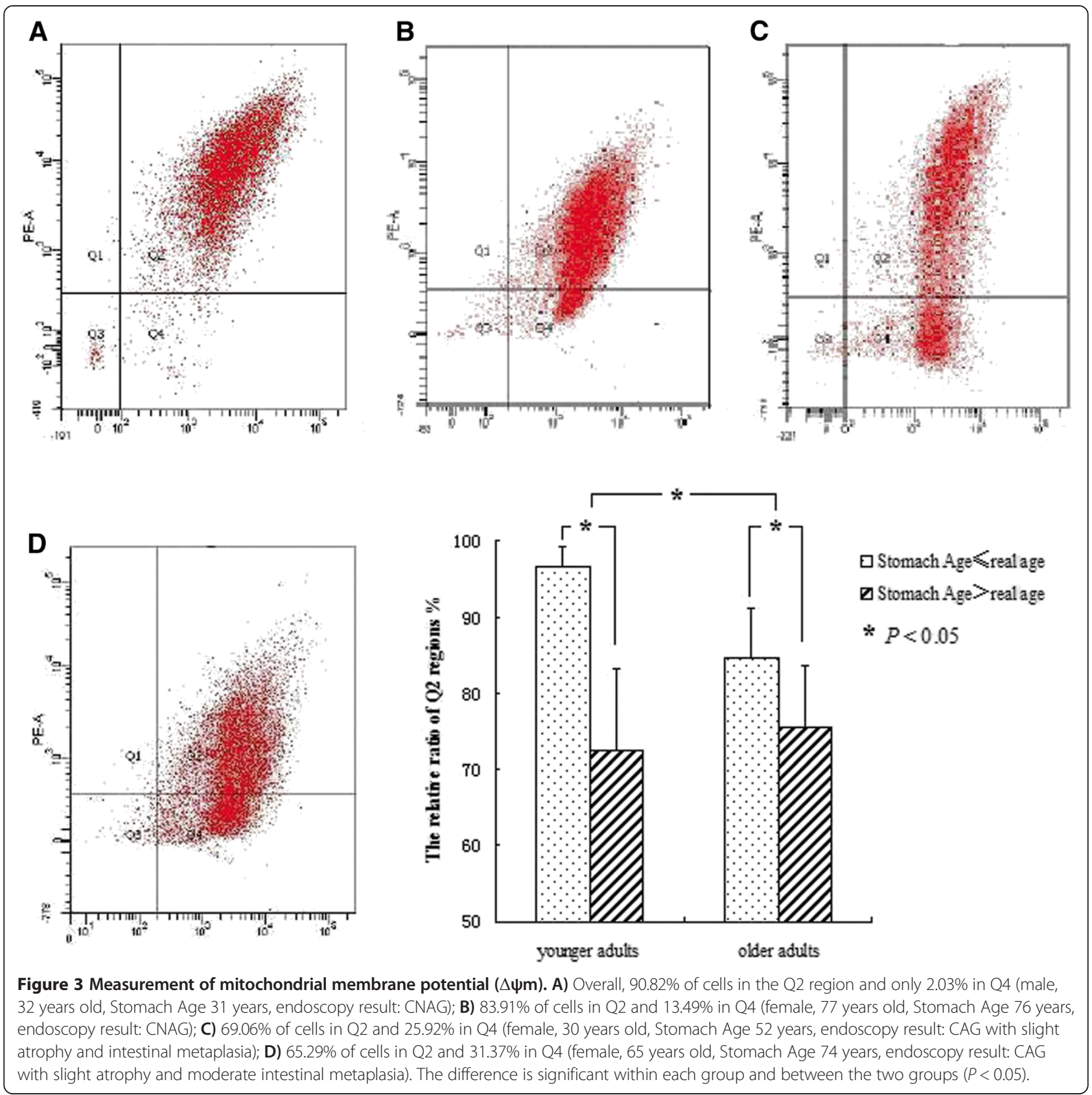

factors and $\Delta$ age (The age calculated from the FISH -real age) were analyzed by multivariate regression analysis using SPSS 17.0. After backward selection, several factors remained in the final model, as shown in Table 3, the Simple Model was found to be:

$$
\begin{aligned}
\Delta \text { age }= & 1.87-0.45 * \mathrm{X} 1-3.39 * \mathrm{X} 2+1.72 * \mathrm{X} 3 \\
& +3.15 * \mathrm{X} 4+13.99 * \mathrm{X} 5+18.62 \\
& * \mathrm{X} 6-16.96 * \mathrm{X} 7+18.16 * \mathrm{X} 8
\end{aligned}
$$

and
Stomach Age $($ years $)=$ real age $+\Delta$ age.

The Hosmer-Lemeshow goodness-of-fit test suggested that the model was well calibrated $(P>0.05)$.

One-hundred and forty-six subjects from multiple centers were used to evaluate the accuracy of the Simple Model. For each subject, Stomach Age was determined using both the samples' intensity on FISH and the Simple Models. The paired $t$-test was used to compare the two results, and no significant difference was found $(P>0.05$, detailed materials were shown in Figure 4), which indicates 
Table 2 The baseline variables and histological evaluation of 120 subjects for the establish model

\begin{tabular}{|c|c|c|c|c|c|c|c|c|c|c|c|c|}
\hline \multirow[b]{3}{*}{ Age range } & \multicolumn{6}{|c|}{ Number of male } & \multicolumn{6}{|c|}{ Number of female } \\
\hline & \multicolumn{6}{|c|}{ (30 out-patients/30 healthy volunteers) } & \multicolumn{6}{|c|}{ (30 out-patients/30 healthy volunteers) } \\
\hline & $<30$ & $30-39$ & $40-49$ & $50-59$ & $60-69$ & $>69$ & $<30$ & $30-39$ & $40-49$ & $50-59$ & $60-69$ & $>69$ \\
\hline Number & 5 & 12 & 14 & 10 & 14 & 5 & 5 & 11 & 17 & 11 & 12 & 4 \\
\hline H.pylori infection positive & 1 & 2 & 1 & 2 & 0 & 0 & 1 & 2 & 3 & 2 & 1 & 0 \\
\hline \multicolumn{13}{|l|}{ Histopathologic results } \\
\hline Atrophy & 2 & 3 & 8 & 1 & 8 & 2 & 2 & 8 & 14 & 5 & 6 & 1 \\
\hline Intestinal metaplasia & 0 & 1 & 4 & 1 & 6 & 1 & 1 & 4 & 10 & 3 & 4 & 1 \\
\hline Mild Dysplasia & 0 & 0 & 0 & 1 & 1 & 1 & 0 & 0 & 1 & 0 & 0 & 0 \\
\hline \multicolumn{13}{|l|}{ Occupation } \\
\hline Students & 2 & 0 & 0 & 0 & 0 & 0 & 3 & 0 & 0 & 0 & 0 & 0 \\
\hline Professional & 0 & 2 & 2 & 1 & 1 & 0 & 0 & 5 & 4 & 1 & 0 & 0 \\
\hline Administrative & 0 & 1 & 1 & 2 & 1 & 0 & 0 & 1 & 5 & 1 & 0 & 0 \\
\hline Sales & 1 & 2 & 1 & 1 & 3 & 0 & 1 & 1 & 2 & 0 & 0 & 0 \\
\hline Blue-collar & 1 & 3 & 5 & 1 & 0 & 0 & 0 & 1 & 1 & 0 & 0 & 0 \\
\hline Freelance & 1 & 4 & 5 & 0 & 2 & 0 & 1 & 3 & 5 & 2 & 7 & 0 \\
\hline Retired & 0 & 0 & 0 & 5 & 7 & 5 & 0 & 0 & 0 & 7 & 5 & 4 \\
\hline High job pressure & 3 & 3 & 4 & 3 & 3 & 0 & 1 & 5 & 8 & 1 & 2 & 0 \\
\hline \multicolumn{13}{|l|}{ Sleeping time } \\
\hline$>8 \mathrm{~h}$ & 1 & 5 & 4 & 2 & 3 & 0 & 1 & 4 & 3 & 5 & 1 & 0 \\
\hline $6-8 \mathrm{~h}$ & 3 & 2 & 5 & 2 & 3 & 5 & 3 & 2 & 7 & 5 & 5 & 2 \\
\hline$<6 \mathrm{~h}$ & 1 & 5 & 5 & 6 & 8 & 0 & 1 & 5 & 7 & 1 & 6 & 2 \\
\hline Poor quality of sleeping & 1 & 4 & 1 & 1 & 2 & 1 & 1 & 2 & 0 & 2 & 1 & 1 \\
\hline \multicolumn{13}{|l|}{ Family history } \\
\hline Stomach cancer & 1 & 0 & 0 & 1 & 0 & 0 & 1 & 0 & 0 & 0 & 0 & 1 \\
\hline Other cancer & 1 & 0 & 1 & 0 & 0 & 0 & 0 & 0 & 0 & 1 & 0 & 0 \\
\hline History of peptic ulcer & 1 & 0 & 1 & 0 & 0 & 0 & 1 & 0 & 2 & 1 & 0 & 0 \\
\hline \multicolumn{13}{|l|}{ Smoking status \& history } \\
\hline Seldom & 0 & 1 & 0 & 1 & 1 & 0 & 0 & 1 & 0 & 0 & 0 & 0 \\
\hline$<10$ cigarettes per day & 0 & 2 & 2 & 1 & 2 & 1 & 0 & 0 & 0 & 0 & 0 & 0 \\
\hline 10-20 cigarettes per day & 0 & 0 & 0 & 0 & 0 & 0 & 0 & 0 & 0 & 0 & 0 & 0 \\
\hline$>20$ cigarettes per day & 0 & 0 & 0 & 0 & 0 & 0 & 0 & 0 & 1 & 0 & 0 & 0 \\
\hline Less than 5 years & 0 & 2 & 0 & 0 & 0 & 0 & 0 & 1 & 0 & 0 & 0 & 0 \\
\hline $5-10$ years & 0 & 1 & 1 & 1 & 0 & 0 & 0 & 0 & 0 & 0 & 0 & 0 \\
\hline More than 10 years & 0 & 0 & 1 & 1 & 3 & 1 & 0 & 0 & 1 & 0 & 0 & 0 \\
\hline Coffee habits & 0 & 1 & 1 & 0 & 0 & 0 & 2 & 2 & 1 & 2 & 1 & 0 \\
\hline Less than 5 years & 0 & 1 & 1 & 0 & 0 & 0 & 2 & 1 & 0 & 1 & 1 & 0 \\
\hline More than 5 years & 0 & 0 & 0 & 0 & 0 & 0 & 0 & 1 & 1 & 1 & 0 & 0 \\
\hline \multicolumn{13}{|l|}{ Tea drinking habits } \\
\hline Green tea & 2 & 4 & 3 & 4 & 2 & 2 & 0 & 3 & 0 & 1 & 0 & 0 \\
\hline Black tea & 0 & 1 & 1 & 0 & 0 & 0 & 0 & 0 & 1 & 2 & 0 & 0 \\
\hline Others & 0 & 0 & 0 & 2 & 0 & 0 & 0 & 0 & 1 & 0 & 0 & 0 \\
\hline Less than 5 years & 1 & 4 & 0 & 3 & 0 & 0 & 0 & 1 & 0 & 0 & 0 & 0 \\
\hline More than 5 years & 1 & 1 & 4 & 3 & 2 & 2 & 0 & 2 & 2 & 3 & 0 & 0 \\
\hline
\end{tabular}


Table 2 The baseline variables and histological evaluation of 120 subjects for the establish model (Continued)

\begin{tabular}{|c|c|c|c|c|c|c|c|c|c|c|c|c|}
\hline Alcohol drinking habits & 0 & 4 & 3 & 2 & 1 & 0 & 0 & 0 & 0 & 0 & 0 & 0 \\
\hline$<250 \mathrm{ml}$ per day & 0 & 2 & 3 & 2 & 0 & 0 & 0 & 0 & 0 & 0 & 0 & 0 \\
\hline$>250 \mathrm{ml}$ per day & 0 & 2 & 0 & 0 & 0 & 0 & 0 & 0 & 0 & 0 & 0 & 0 \\
\hline Less than 5 years & 0 & 3 & 0 & 0 & 0 & 0 & 0 & 0 & 0 & 0 & 0 & 0 \\
\hline More than 5 years & 0 & 1 & 3 & 2 & 1 & 0 & 0 & 0 & 0 & 0 & 0 & 0 \\
\hline Spicy flavors & 1 & 2 & 2 & 1 & 0 & 0 & 1 & 3 & 3 & 2 & 1 & 1 \\
\hline Regular meals & 5 & 5 & 9 & 6 & 8 & 4 & 1 & 5 & 7 & 6 & 10 & 4 \\
\hline \multicolumn{13}{|l|}{ Lengths of meals } \\
\hline$<10$ minutes & 4 & 4 & 5 & 2 & 1 & 0 & 3 & 2 & 5 & 4 & 3 & 0 \\
\hline 10-30 minutes & 0 & 8 & 8 & 3 & 10 & 2 & 2 & 3 & 10 & 5 & 8 & 1 \\
\hline$>30$ minutes & 1 & 0 & 1 & 5 & 3 & 3 & 0 & 6 & 2 & 2 & 1 & 3 \\
\hline Drinking liquid at eating time & 2 & 5 & 8 & 6 & 5 & 2 & 5 & 3 & 10 & 2 & 3 & 2 \\
\hline Consumption of milk & 2 & 7 & 7 & 5 & 4 & 2 & 3 & 9 & 8 & 5 & 6 & 2 \\
\hline \multicolumn{13}{|l|}{ Consumption $>2$ per week } \\
\hline Salted fermented products & 0 & 5 & 3 & 4 & 7 & 2 & 1 & 5 & 5 & 6 & 4 & 1 \\
\hline Desserts & 2 & 2 & 3 & 0 & 3 & 0 & 4 & 2 & 4 & 3 & 1 & 0 \\
\hline Dehydrated foods & 2 & 3 & 3 & 0 & 1 & 0 & 2 & 4 & 2 & 1 & 0 & 0 \\
\hline Fried foods & 1 & 6 & 2 & 2 & 1 & 0 & 3 & 4 & 8 & 4 & 4 & 0 \\
\hline Leftovers & 2 & 6 & 6 & 3 & 10 & 5 & 0 & 4 & 11 & 9 & 5 & 1 \\
\hline Seafood & 1 & 7 & 7 & 1 & 2 & 0 & 3 & 5 & 3 & 2 & 3 & 1 \\
\hline Pickled vegetables & 0 & 1 & 0 & 2 & 3 & 2 & 0 & 2 & 4 & 6 & 2 & 2 \\
\hline
\end{tabular}

that the Simple Model can be used in clinical practice instead of the FISH.

\section{The relationship between $\Delta$ age and prognosis in a large} sample study

Overall, 1,200 patients were recruited in the study, subjects were asked to reply to the standard questionnaire, which encompassed the eight factors in the Simple Model of Stomach Age, by telephone or letter. A total of 1,007 subjects, 457 male and 560 female, returned completed questionnaires. The average duration of follow-up was 5.4 years (range, 12 months to 190 months).
We calculated the Stomach Age of each subject by the Simple Model, and the $\Delta$ age were recorded. The histological results at the beginning and the end of the follow-up period were compared individually. On the basis of the comparison of histological results, 1,007 subjects were divided into three groups: Group A (329 subjects), whose histological results had improved after follow-up as the degree of inflammation or/and atrophy or/and IM was reduced after; Group B (320 subjects), in whom there was no change after follow-up; and Group C (358 subjects), whose biopsy results worsened, meaning the degree of inflammation or/and atrophy or/and

Table 3 Multivariate logistic regression model for simple Stomach Age

\begin{tabular}{|c|c|c|c|c|}
\hline Variable & Parameter estimate & Standard error & F value & $\operatorname{Pr}>\mathrm{F}$ \\
\hline Intercept & 1.8704 & 0.4832 & 16.68 & $<.0001$ \\
\hline \multicolumn{5}{|l|}{ Pathological result of endoscopy } \\
\hline $\mathrm{X} 1$ inflammation & -0.44783 & 0.25975 & 11.27 & 0.0010 \\
\hline $\mathrm{X} 2$ activity & -3.39746 & 1.84974 & 6.19 & 0.0139 \\
\hline X3 atrophy & 1.71968 & 0.76847 & 8.81 & 0.0035 \\
\hline X4 intestinal metaplasia (none 0 , mild 1 , moderate 2 , severe 3 ) & 3.15415 & 1.59460 & 15.99 & 0.0001 \\
\hline X5 family history of gastric cancer (yes 1, no 0 ) & 13.99844 & 5.82543 & 5.77 & 0.0202 \\
\hline X6 accompany with cardiovascular disease (yes 1, no 0) & 18.62093 & 5.95565 & 9.78 & 0.0030 \\
\hline X7 accompany with Gastro-esophageal reflux disease (yes 1, no 0) & -16.95696 & 4.90988 & 13.09 & 0.0004 \\
\hline X8 times of fast and junk food per week & 18.16387 & 3.57430 & 10.55 & 0.0014 \\
\hline
\end{tabular}




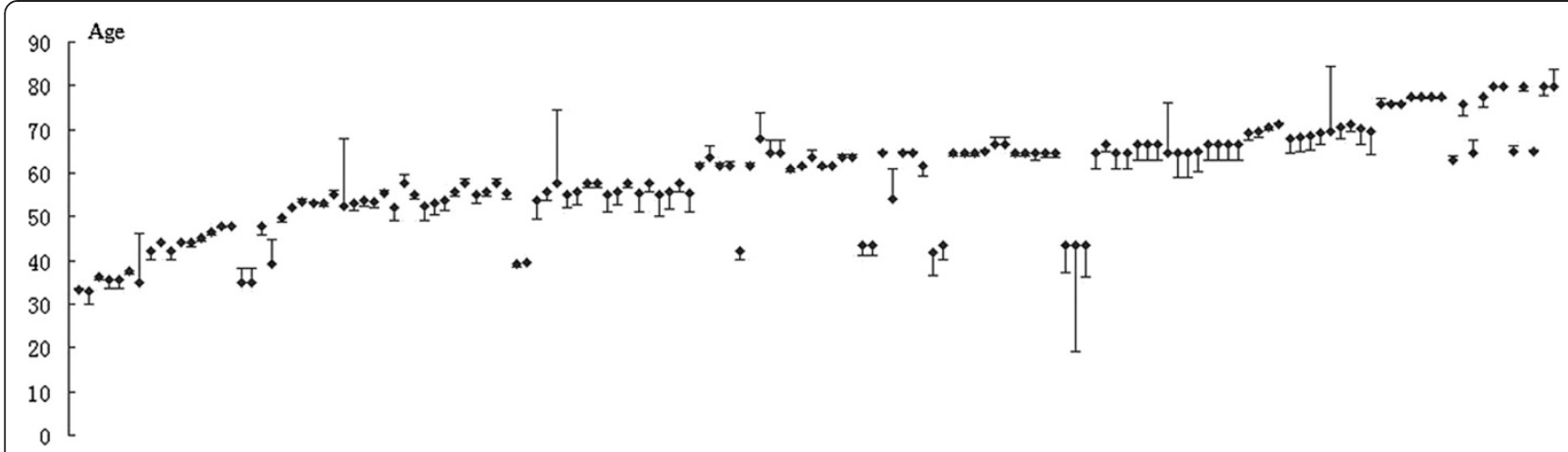

Figure 4 No significant difference was found between the Simple Model and the FISH data $(\mathbf{n}=\mathbf{1 4 6})$. For each subject, Stomach Age was determined using both the samples' intensity on FISH and the Simple Models. Each dot represents a subject. The error bars represent the difference between the biological age which calculated from the samples' intensity on FISH and the Simple Models of Stomach Age. Almost all of the subjects showed a short error bars which indicates that the Simple Model can be used in clinical practice instead of the FISH. The paired $t$-test was used to compare the two results, and no significant difference was found $(P>0.05)$.

IM had increased, and newly emerging atrophy or/and IM was present.

We found that in Group A, the majority of subjects (75.99\%) were $\Delta$ age $\leq 0$ (Stomach Age was younger than or equal to their real age), and on the contrary, the majority of subjects in Group C (88.82\%) were $\Delta$ age $>0$ (Stomach Age was greater than their real age). In multiple comparisons, there was a significant difference between these three groups $(P<0.01$; Figure 5$)$.

After this, we divided the 1,007 subjects into subgroups according to their real age in order to observe whether there was a significant impact on prognosis according to Stomach Age. The results showed that Stomach Age could influence the prognosis of disease at all biological ages analyzed (Table 4).

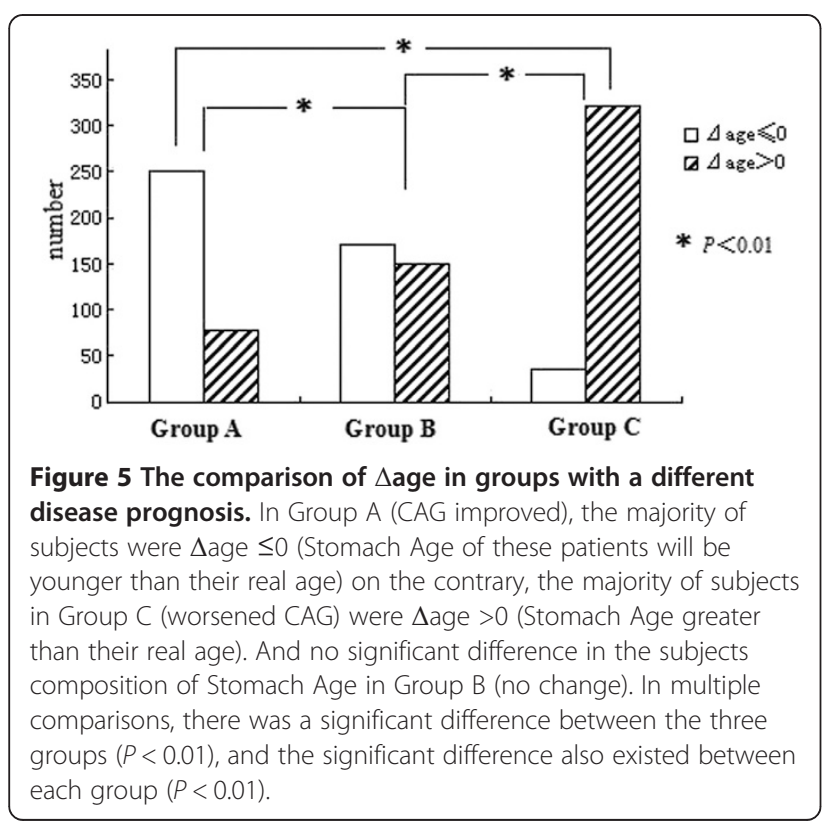

Evaluate the predictive ability of the Simple Model of Stomach Age

Using the Simple Model of Stomach Age, we obtained a new variable $(\Delta$ age $)$ for all participants. We used the pathological diagnosis as the gold standard, and divided the 1,007 subjects into two groups: the poor prognosis group (Group C) or better prognosis group (Groups A and $\mathrm{B}$ on histology). Then, we analyzed the model by the ROC curve and calculated the AUROC. The model showed relatively good discrimination, with an AUROC of 0.852 (95\% CI, 0.829-0.876; Figure 6).

The sensitivity and specificity were calculated using various cut-off points ranging from 0.0 to 1.0 . We chose the Youden's index cut-off point that corresponded to the maximal value as the new standard. A final probability cut-off score of 3.11 was used to predict those at a high risk of a poor prognosis $(>3.11)$ or a low risk of a poor prognosis $(\leq 3.11)$. The sensitivity and specificity were $82.7 \%$ and $71.8 \%$, respectively.

Finally, we analyzed the effects of $\Delta$ age on prognosis using the Kaplan-Meier Survival Model (Figure 6). The comparisons revealed that higher $\Delta$ age $(>3.11)$ was associated with poor prognosis $(P<0.01)$. This results indicated that attention should be paid to those patients whose $\Delta$ age $>3.11$, due to the potential poor prognosis.

\section{Discussion}

Aging is the progressive loss of metabolic and physiological functions, but its trajectory is not uniform, which suggests considerable variation exists in its biology [25]. This theory provides the basis of the concept of Stomach Age. People of the same biological age may have different Stomach Ages, and this variation may arise from a host of genetic and environmental factors. With the use of Stomach Age, we can differentiate between normal and abnormal stomach aging (the CAG in younger adults). 
Table 4 The comparasions between groups of different age

\begin{tabular}{|c|c|c|c|c|c|c|c|c|c|c|c|c|c|}
\hline \multirow[t]{2}{*}{ Age } & & \multicolumn{2}{|c|}{$20-39$} & \multicolumn{2}{|c|}{$40-49$} & \multicolumn{2}{|c|}{$50-59$} & \multicolumn{2}{|c|}{$60-69$} & \multicolumn{2}{|c|}{$70-79$} & \multicolumn{2}{|c|}{$\geq 80$} \\
\hline & & $\overline{\mathrm{N}^{*}}$ & $P^{\#}$ & $\overline{\mathrm{N}}$ & $P$ & $\bar{N}$ & $P$ & $\bar{N}$ & $P$ & $\bar{N}$ & $P$ & $\overline{\mathrm{N}}$ & $P$ \\
\hline \multirow[t]{2}{*}{ GroupA } & $\Delta$ age $\leq 0$ & 8 & & 25 & & 75 & & 79 & & 53 & & 12 & \\
\hline & $\Delta$ age $>0$ & 2 & & 6 & & 27 & & 29 & & 7 & & 6 & \\
\hline \multirow[t]{2}{*}{ GroupB } & $\Delta$ age $\leq 0$ & 4 & 0.046 & 24 & 0.000 & 64 & 0.000 & 54 & 0.000 & 18 & 0.000 & 6 & 0.000 \\
\hline & $\Delta$ age $>0$ & 8 & & 16 & & 50 & & 52 & & 17 & & 7 & \\
\hline \multirow[t]{2}{*}{ GroupC } & $\Delta$ age $\leq 0$ & 2 & & 7 & & 7 & & 11 & & 8 & & 1 & \\
\hline & $\Delta$ age $>0$ & 4 & & 24 & & 67 & & 126 & & 68 & & 33 & \\
\hline
\end{tabular}

N $\mathrm{N}=$ number of patients.

${ }^{\#} P=P$ value.

Telomere length in proliferative somatic cells is inversely correlated with age [26], and therefore the variation in Stomach Age recorded by FISH analysis of stomach biopsy samples could be an accurate means of describing the age of the stomach. According to our study, CAG patients have relatively shorter telomeres than normal and the Stomach Age of these patients is greater than their real age, which indicates that CAG could be regarded as a form of stomach aging. Thus, CAG in younger adults could be considered as premature aging of the stomach, which is a pathological process, and the mechanism of CAG in younger adults is quite different from that in more elderly people.
Further evidence to support this view is that the $\Delta \psi \mathrm{m}$ in CAG patients was significantly decreased, especially in younger adults. After exposure to the oxidative damage that is thought to contribute to aging, mitochondria are disproportionately damaged or destroyed and cannot maintain their $\Delta \psi \mathrm{m}$ [27]. This phenomena exists not only in many degenerative diseases (e.g., Parkinson's disease) [28], but also in aging cells [29]. Our finding that the presence of CAG increased the decline of $\Delta \psi \mathrm{m}$, especially in younger adults $(P<0.05)$; this indicates that CAG may accelerate aging in the stomach, leading to a greater Stomach Age. From these results, we hypothesize that $\Delta$ age (Stomach Age - real age) could predict the

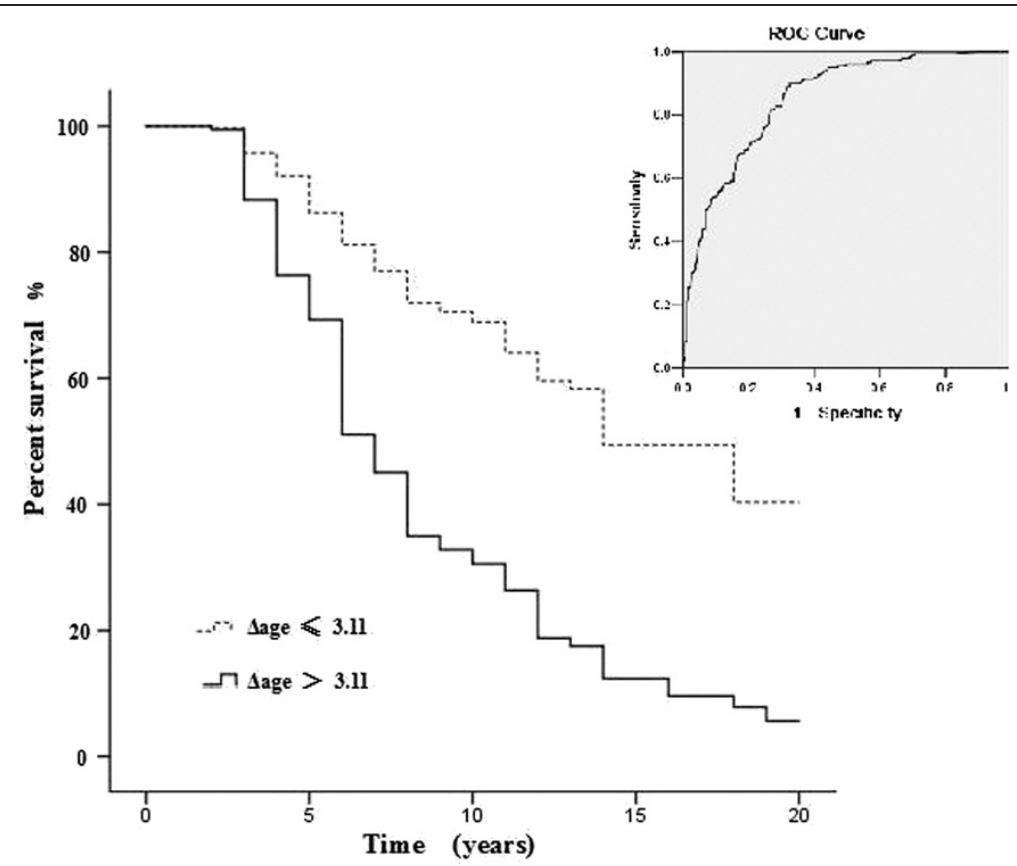

Figure 6 ROC curve and Kaplan-Meier survival curve of the accuracy of $\Delta$ age for prognostication $(\mathbf{n}=1007)$. The AUROC was 0.852 (95\% Cl 0.829-0.876), which indicates relatively good discrimination. It is analyzed using Kaplan-Meier survival model, including 649 cases with $\Delta$ age $\leq 3.11$, and 358 cases with $\Delta$ age $>3.11$. The result revealed that higher $\Delta$ age $(>3.11)$ was associated with poor prognosis. The Chi-square test indicated that there was significant difference between the two groups $(P<0.01)$. 
severity of CAG and a higher $\triangle$ age indicates abnormal aging of the stomach.

Moreover, age has been established as an independent risk factor for the development of gastric cancer in CAG patients, and a recent large cohort study showed that the age at the initial diagnosis was associated with the progression to more advanced lesions and to gastric cancer [30]. We hypothesize that those with abnormal biological stomach aging would have an increased risk of gastric cancer than those with a normal Stomach Age.

Although Stomach Age can be determined by FISH, the use of this method in large populations is unrealistic due to its high cost. For this reason, we modified the equation by logistic regression to obtain a simple form for clinical use. The questionnaire we used included numerous factors related to gastritis, which has been validated in previous studies [31-34]. To summary, firstly,we focused on eight factors that affect Stomach Age by using logistic regression (Table 3). There was no doubt that the endoscopy results influenced the model. Atrophy and IM can increase Stomach Age, whereas inflammation and its activity had no effect. Studies have shown that CAG is likely to advance gradually with increasing age, even in asymptomatic subjects [35] and there was an upward age-related trend of the prevalence of IM with increasing age [36], which is consistent with our results. Secondly, a family history of gastric cancer may also increase Stomach Age. The relationship between the family history of gastric cancer and the risk of CAG is controversial $[37,38]$. Our results support the idea that a family history of gastric cancer can accelerate aging of the stomach, which may lead to increased CAG. Thirdly, it is interesting that, in people with cardiovascular disease, aging of the stomach is accelerated, whereas the presence of gastroesophageal reflux disease (GERD) seems to have the reverse effect. This might be the result of hyperhomocysteinemia [39]. In addition, certain medications for the treatment of cardiovascular disease, such as aspirin, can cause gastric damage both through topical irritant effects on the epithelium and by systemic effects related to the suppression of mucosal prostaglandin synthesis [40], and thus may also lead to aging of the stomach. Aging is reported to be correlated with esophageal motor abnormalities such as GERD [41], but our findings are not the same. We hypothesize that our model for the determination of Stomach Age is more focused on secretion than on motor ability, as it is based on FISH measurements of telomere lengths, which are greater in normal epithelial cells than atrophic tissues. The mucosa and secretory glands are relatively complete in GERD; whether this has any effect on the measured Stomach Age should be investigated in future studies. Finally, junk food may also play an important role in Stomach Age. A recent study reported that trans fats, which are common in fast food, can accelerate brain aging [42]. We hypothesize that foods containing synthetic additives, such as preservatives, or those with a high fat content could also increase the Stomach Age.

Our study did not find any significant relationship between $H$. pylori infection and aging, which differs from the results of other studies [43,44]. There are at least two possible reasons. Firstly, because most of our patient information came from a cross-sectional study, $H$. pylori infection could have been present once but have been eliminated at the time of the biopsies. Another explanation is that the gastric environment no longer suited the growth conditions of $H$. pylori, and the bacteria could not survive in conditions with extensive atrophy $[45,46]$.

In order to evaluate validity of the Simple Model of Stomach Age, we compared it with the results of FISH intensity by paired- $t$ test which indicated no difference between them. The ability to predict disease's prognosis of Simple Model was evaluated by ROC curve with large sample number, in which the cut-off point of $\Delta$ age $>3.11$ is used to predict the high risk of getting poor prognosis (sensitivity and specificity of $82.7 \%$ and $71.8 \%$, respectively). That means those patients with $\Delta$ age $>3.11$ may develop to a worse prognosis in the future which should be closely follow-up and regularly examination of endoscopy should be provided to them.

However, the majority of CAG patients observed for a maximum of 16.5 years did not develop gastric cancer [30], which suggested that a surveillance program for all CAG patients may not be cost-effective. Our results showed that a subset of patients at a higher risk for GC could be easily identified by using the cut-off of $\Delta$ age $>3.11$ at the time of the CAG diagnosis, which potentially enables these patients $(\Delta$ age $>3.11)$ to be selected for warranted endoscopy surveillance without unnecessarily increasing the healthcare costs in this field.

\section{Conclusion}

In conclusion, this study provides a definition of Stomach Age, and demonstrates that people of the same true age may have different Stomach Ages. Attention should be paid to those with a greater Stomach Age than expected, especially in younger adults, as their mechanism of CAG is pathologically different to those in elderly patients, with a greater risk of developing gastric cancer over a lifetime. The $\Delta$ age as calculated from the Simple Model was related to the prognosis for developing worsened CAG and the cut-off of $>3.11$ should be considered as a criterion to select a subgroup of CAG patients for gastric cancer surveillance.

Competing interests

The authors declare that there is no conflict of interests. 


\section{Authors' contributions}

Q-YG, Z-HW, YC (study concept and design; analysis and interpretation of data; drafting of the manuscript; critical revision of the manuscript for important intellectual content). J-QS, K-HZ, R-HS, J-MX, W-CC, X-LZ, S-DL, Y-XC (acquisition of data). Y-YS (statistical analysis). J-YF (study concept and design; study supervision). All authors read and approved the final manuscript.

\section{Acknowledgement}

This project was supported by grants from the National Basic Research Program of China 973 program Grant (No. 2010CB5293), the National High Technology Research and Development Program of China (863 Program) (Grant No. 2012AA02A504), and National Natural Science Foundation of China (Grant No. 81302085).

\section{Author details}

${ }^{1}$ GI Division, Renji Hospital, Shanghai Jiao-Tong University School of Medicine, Shanghai Institution of Digestive Disease, 145 Middle Shandong Rd, Shanghai 200001, China. ${ }^{2}$ Key Laboratory of Gastroenterology \& Hepatology, Ministry of Health, Shanghai Jiao-Tong University, 145 Middle Shandong Rd, Shanghai 200001, China. ${ }^{3}$ State Key Laboratory of Oncogene and Related Genes, 145 Middle Shandong Rd, Shanghai 200001, China. ${ }^{4}$ The Military General Hospital of Beijing PLA, 5 East sishitiao nanmencang, Beijing 100700, China. ${ }^{5}$ The First Affiliated Hospital of NanChang University, 17 Yongwaizheng Street, Nanchang 330006, China. ${ }^{6}$ The First Affiliated Hospital of NanJing Medical University, 300 Guangzhou Rd, Nanjing 210029, China. ${ }^{7}$ The First Affiliated Hospital of Anhui University, 218 Jixi Rd, Hefei 230022, China. ${ }^{8}$ The First Affiliated Hospital of SooChow University, 188 Shizi Street, Suzhou 215006, China. ${ }^{9}$ Qilu Hospital of Shandong University, 107 West Wenhua Rd, Jinan 250012, China. ${ }^{10}$ Second Military Medical University Changhai Hospital, 168 Changhai Rd, Shanghai 200433, China. ${ }^{11}$ Second Military Medical University Changzheng Hospital, 415 Fengyang Rd, Shanghai 200003, China. ${ }^{12}$ Department of Statistics, Shanghai Jiao-Tong University School of Medicine, 227 South Chongqing Rd, Shanghai 200025, China.

Received: 4 November 2012 Accepted: 23 June 2014

Published: 28 June 2014

\section{References}

1. Inoue M, Tajima K, Matsuura A, Suzuki T, Nakamura T, Ohashi K, Nakamura S, Tominaga S: Severity of chronic atrophic gastritis and subsequent gastric cancer occurrence: a 10-year prospective cohort study in Japan. Cancer Lett 2000, 161:105-112.

2. Sipponen $P$ : Natural history of gastritis and its relationship to peptic ulcer. Digestion 1992, 51(Suppl 1):70-75.

3. Boss GR, Seegmiller JE: Age-related physiological changes and their clinical significance. West J Med 1981, 135:434-440.

4. Weck MN, Brenner H: Prevalence of chronic atrophic gastritis in different parts of the world. Cancer Epidemiol Biomarkers Prev 2006, 15:1083-1094.

5. Blackburen EH: Switching and signaling at the telomere. Cell 2001, 106:661-667.

6. Benetos A, Okuda K, Lajemi M, Kimura M, Thomas F, Skurnick J, Labat C, Bean $\mathrm{K}$, Aviv A: Telomere length as an indicator of biological aging: the gender effect and relation with pulse pressure and pulse wave velocity. Hypertension 2001, 37:381-385.

7. Adaikalakoteswari A, Balasubramanyam M, Mohan V: Telomere shortening occurs in Asian Indian Type 2 diabetic patients. Diabet Med 2005, 22:1151-1156.

8. Starr JM, McGurn B, Harris SE, Whalley LI, Deary IJ, Shiels PG: Association between telomere length and heart disease in a narrow age cohort of older people. Exp Gerontol 2007, 42:571-573.

9. Kammori M, Nakamura K, Kawahara M, Mimura Y, Kaminishi M, Takubo K: Telomere shortening with aging in human thyroid and parathyroid tissue. Exp Gerontol 2002, 37:513-521.

10. Gilson E, Londoño-Vallejo A: Telomere length profiles in humans. Cell Cycle 2007, 6:2486-2494.

11. Allsopp RC, Chang E, Kashefi-Aazam M, Rogaev El, Piatyszek MA, Shay JW, Harley CB: Telomere shortening is associated with cell division in vitro and in vivo. Exp Cell Res 1995, 220(1):194-200.

12. Hastie ND, Dempster M, Dunlop MG, Thompson AM, Green DK, Allshire RC: Telomere reduction in human colorectal carcinoma and with ageing. Nature 1990, 346:866-868.
13. Norwood D, Dimitrov DS: Sensitive method for measuring telomere lengths by quantifying telomeric DNA content of whole cells. Biotechniques 1998, 25:1040-1045.

14. Lansdorp PM, Verwoerd NP, van de Rijke FM, Dragowska V, Little MT, Dirks RW, Raap AK, Tanke HJ: Heterogeneity in telomere length of human chromosomes. Hum Mol Genet 1996, 5:685-691.

15. Meeker AK, Gage WR, Hicks JL, Simon I, Coffman JR, Platz EA, March GE, De Marzo AM: Telomere length assessment in human archival tissues: combined telomere fluorescence in situ hybridization and immunostaining. Am J Pathol 2002, 160:1259-1268.

16. Dixon Michael F, Genta Robert M, Yardley John H, Correa P: Classification and grading of gastritis: the updated Sydney system. Am J Surg Pathol 1996, 20:1161-1181.

17. Meeker AK, Hicks JL, Platz EA, March GE, Bennett CJ, Delannoy MJ, De Marzo AM: Telomere shortening is an early somatic DNA alteration in human prostate tumorigenesis. Cancer Res 2002, 62(22):6405-6409.

18. Hansel DE, Meeker AK, Hicks J, De Marzo AM, Lillemoe KD, Schulick R, Hruban RH, Maitra A, Argani P: Telomere length variation in biliary tract metaplasia, dysplasia, and carcinoma. Mod Pathol 2006, 19(6):772-779.

19. van Heek NT, Meeker AK, Kern SE, Yeo CJ, Lillemoe KD, Cameron JL, Offerhaus GJ, Hicks JL, Wilentz RE, Goggins MG, De Marzo AM, Hruban RH, Maitra A: Telomere shortening is nearly universal in pancreatic intraepithelial neoplasia. Am J Pathol 2002, 161(5):1541-1547.

20. Dong W, Cheng S, Huang F, Fan W, Chen Y, Shi H, He H: Mitochondrial dysfunction in long-term neuronal cultures mimics changes with aging. Med Sci Monit 2011, 17(4):BR91-BR96.

21. Ozawa T: Mitochondrial Genome Mutation in Cell Death and Aging. J Bioenerg Biomembr 1999, 31(4):377-390.

22. Hosmer DW, Lemeshow S: Model-building strategies. In Applied logistic regression. Edited by Sons JW. New York: A Wiley interscience Publication; 1989:82-134.

23. Dodd LE, Pepe MS: Partial AUC estimation and regression. Biometrics 2003, 59:614-623.

24. Kennedy SR, Loeb LA, Herr AJ: Somatic mutations in aging, cancer and neurodegeneration. Mech Ageing Dev 2012, 133(4):118-126.

25. Kirkwood T, Austad S: Why do we age? Nature 2000, 408:233-238,

26. Aviv A: Telomeres and human aging: facts and fibs. Sci. Sci Aging Knowledge Environ 2004, 2004(51):pe43.

27. Ames BN, Shigenaga MK, Hagen TM: Mitochondrial decay in aging. Biochim Biophys Acta 1995, 1271:165-170.

28. Sugrue MM, Tatton WG: Mitochondrial membrane potential in aging cells. Biol Signals Recept 2001, 10:176-188.

29. Martinez AO, Over D, Armstrong LS, Manzano L, Taylor R, Chambers J: Separation of two subpopulations of old human fibroblasts by mitochondria (rhodamine 123) fluorescence. Growth Dev Aging 1991, 55:185-191.

30. de Vries AC, van Grieken NC, Looman CW, Casparie MK, de Vries E, Meijer GA, Kuipers EJ: Gastric cancer risk in patients with premalignant gastric lesions: a nationwide cohort study in the Netherlands. Gastroenterology 2008, 134:945-952.

31. Inoue M, Tajima K, Kobayashi S, Suzuki T, Matsuura A, Nakamura T, Shirai M, Nakamura S, Inuzuka K, Tominaga S: Protective factor against progression from atrophic gastritis to gastric cancer-Data from a cohort study in Japan. Int J Cancer 1996, 66:309-314.

32. Zhao L, Blot WJ, Liu WD, Chang YS, Zhang JS, Hu YR, You WC, Xu GW, Fraumeni JF Jr: Familial predisposition to precancerous gastric lesions in a high-risk area of China. Cancer Epidemiol Biomarkers Prev 1994, 3:461-464.

33. The Eurohepygast Study Group: Risk factors for atrophic chronic gastritis in a European population: results of the Eurohepygast study. Gut 2002, 50:779-785.

34. Setiawan WW, Zhang ZF, Yu GP, Lu QY, Li YL, Lu ML, Wang MR, Guo CH, Yu SZ, Kurtz RC, Hsieh CC: Protective effect of green tea on the risks of chronic gastritis and stomach cancer. Int J Cancer 2001, 92:600-604.

35. Kohli Y, Kato T, Suzuki K, Tada T, Fujiki N: Incidence of atrophic gastritis with age in Japan and Canada. Jpn J Med 1987, 26:158-161.

36. Tsukui T, Kashiwagi R, Sakane M, Tabata F, Akamatsu T, Wada K, Futagami S, Miyake K, Sueoka N, Hirakawa T, Kobayashi M, Fujimori T, Sakamoto C: Aging increases, and duodenal ulcer reduces the risk for intestinal metaplasia of the gastric corpus in Japanese patients with dyspepsia. J Gastroenterol Hepatol 2001, 16:15-21.

37. Vannella L, Lahner E, Osborn J, Bordi C, Miglione M, Delle Fave G, Annibale $B$ : Risk factors for progression to gastric neoplastic lesions in patients with atrophic gastritis. Aliment Pharmacol Ther 2010, 31:1042-1050. 
38. Adamu MA, Weck MN, Rothenbacher D, Brenner H: Incidence and risk factors for the development of chronic atrophic gastritis: five year follow-up of a population-based cohort study. Int I Cancer 2011 128:1652-1658.

39. Redeen S, Ryberg A, Petersson F, Eriksson O, Nägga K, Borch K: Homocysteine levels in chronic gastritis and other conditions: relations to incident cardiovascular disease and dementia. Dig Dis Sci 2009, 55:351-358.

40. Cryer B, Feldman M: Effects of very low dose daily, long-term aspirin therapy on gastric, duodenal, and rectal prostaglandin levels and on mucosal injury in healthy humans. Gastroenterolgy 1999, 117:17-25.

41. Gutschow CA, Leers JM, Schröder W, Prenzel KL, Fuchs H, Bollschweiler E, Bludau M, Hölscher AH: Effect of aging on esophageal motility in patients with and without GERD. Ger Med Sci 2011, 9:Doc22. Epub 2011 Aug 18.

42. Bowman GL, Silbert LC, Howieson D, Dodge HH, Traber MG, Frei B, Kaye JA, Shannon J, Quinn JF: Nutrient biomarker patterns, cognitive function, and MRI measures of brain aging. Neurology 2012, 78(4):241-249.

43. Fontham ET, Ruiz B, Perez A, Hunter F, Correa P: Determinants of Helicobacter pylori infection and chronic gastritis. Am J Gastroenterol 1995, 90:1094-1101.

44. Asaka M, Kimura T, Kudo M, Takeda H, Mitani S, Miyazaki T, Miki K, Graham DY: Relationship of Helicobacter pylori to serum pepsinogens in an asymptomatic Japanese population. Gastroenterology 1992, 102:760-766.

45. Wyatt JI, Shallcross TM, Crabtree JE, Heatley RV: Helicobacter pylori, gastritis, and peptic ulceration in the elderly. J Clin Pathol 1992, 45:1070-1074.

46. Tsugane S, Kabuto M, Imai H, Gey F, Tei Y, Hanaoka T, Sugano K, Watanabe S: Helicobacter pylori, dietary factors, and atrophic gastritis in five Japanese populations with different gastric cancer mortality. Cancer Causes Control 1993, 4:297-305.

doi:10.1186/1472-6890-14-29

Cite this article as: Gao et al: Evaluation and clinical significance of the stomach age model for evaluating aging of the stomach-a multicenter study in China. BMC Clinical Pathology 2014 14:29.

\section{Submit your next manuscript to BioMed Central and take full advantage of:}

- Convenient online submission

- Thorough peer review

- No space constraints or color figure charges

- Immediate publication on acceptance

- Inclusion in PubMed, CAS, Scopus and Google Scholar

- Research which is freely available for redistribution 